\title{
Accumulation of Chiro-inositol and Other Non-structural Carbohydrates in Limonium Species in Response to Saline Irrigation Waters
}

\author{
Xuan Liu ${ }^{1}$ and Catherine Grieve \\ U.S. Department of Agriculture-Agricultural Research Service, U.S. Salinity Laboratory, \\ 450 West Big Springs Road, Riverside, CA 92507
}

\begin{abstract}
AdDitional INDEX wORDs. fructose, glucose, Limonium perezii, Limonium sinuatum, myo-inositol, phloem transportation, starch, statice, sucrose

Abstract. Two statice cultivars, Limonium perezii cv. Blue Seas and L. sinuatum cv. American Beauty, were grown in greenhouse sand tanks to determine the effect of salt stress on carbohydrate accumulation and partitioning. For the first experiment, irrigation waters were prepared to simulate typical saline-sodic drainage effluent in the San Joaquin Valley of California with electrical conductivities of $2.5,7,11,15,20,25$, and $30 \mathrm{dS} \cdot \mathrm{m}^{-1}$. A second experiment compared responses to two types of irrigation waters with salinity levels of $2.5,6,8,10,12,16$, and $\left.20 \mathrm{dS} \cdot \mathrm{m}^{-1}: 1\right) \mathrm{San}$ Joaquin Valley drainage waters, and 2) solutions mimicking concentrations of Colorado River water, a major irrigation water source for southern California. In addition to the presence of $m y o$-inositol and three common sugars (fructose, glucose, and sucrose), chiro-inositol was for the first time isolated and identified in leaf and root tissues of both Limonium species. As salinity increased from 2.5 to $30 \mathrm{dS} \cdot \mathrm{m}^{-1}$, leaf chiro-inositol concentration increased from 6.4 to 52.8 and from 2.6 to $72.9 \mu \mathrm{mol} \cdot \mathrm{g}^{-1}$ dry weight for $L$. perezii and $L$. sinuatum, respectively, suggesting that chiroinositol contributes substantially to osmotic adjustment in the stressed plants. Meanwhile, leaf myo-inositol concentration remained low in both species and showed little response to salinity. Before salt stress, the seedlings contained little chiro-inositol, indicating that salt enhanced chiro-inositol synthesis per unit of biomass formation. Significant $(P \leq \mathbf{0 . 0 5})$ increasing trends for fructose and glucose and a decreasing trend for sucrose with increasing salinity were observed in the leaves of $L$. perezii but not $L$. sinuatum. As a result, the leaves of $L$. perezii had higher glucose and fructose but lower sucrose levels than that of $L$. sinuatum. However, no significant $(P>0.05)$ salt effect was found on the sum of the three common sugar concentrations in either species. Therefore, the accumulation of chiroinositol resulted in a change in carbon partitioning among the soluble carbohydrates (i.e., the ratio of leaf chiroinositol over a sum of the three common sugars rose from 0.034 to $0.29 \mathrm{dS} \cdot \mathrm{m}^{-1}$ and from 0.012 to $0.32 \mathrm{dS} \cdot \mathrm{m}^{-1}$ for $L$. perezii and $L$. sinuatum, respectively, as salinity increased from 2.5 to $30 \mathrm{dS} \cdot \mathrm{m}^{-1}$ ). Salt stress did not affect starch accumulation and caused no carbon reserve deficiency. Furthermore, it was observed that salinity increased chiroinositol phloem transport. The chiro-inositol response might be a physiological process for Limonium salt adaptation. The types of saline irrigation waters (i.e., sodium sulfate-dominated waters vs. a sodium chloride system) appear to have little effect on carbohydrate accumulation and partitioning in L. perezii.
\end{abstract}

Improvement of plant salt tolerance relies greatly on understanding how plants deal with salt stress through physiological and biochemical responses. In addition to specific ion toxicity, salinity causes water stress via lowering osmotic potential $\left(\psi_{\mathrm{S}}\right)$ in root media. Under salt stress, halophytes may take up and compartmentalize inorganic ions into vacuoles to prevent saltinduced inhibition of enzymatic activities in the cytoplasm (Flowers et al., 1986). High vacuolar ion accumulation lowers cell $\psi_{\mathrm{S}}$, which facilitates cell water retention and uptake and thus maintains cell turgor. This is balanced by cytoplasmic water potential adjustment through accumulation of large quantities of specific metabolic osmotica or compatible solutes (Glenn et al., 1999). This mechanism for plant adaptation to salinity and survival under high salt stress is well recognized (Popp and

We thank Drs. Mary Lu Arpaia, David Grantz, and John D. Williamson for critical review of the manuscript, and Mr. Yi Meng for operating the NMR spectrometer during the course of cyclitol detection.

Received for publication 25 Feb. 2009. Accepted for publication 13 Apr. 2009. Mention of company names or products is for the benefit of the reader and does not imply endorsement, guarantee, or preferential treatment by the USDA or its agents.

${ }^{1}$ Corresponding author. E-mail: Xuan.liu@ars.usda.gov.
Smirnoff, 1995). In addition to lowering $\psi_{\mathrm{S}}$, compatible solutes can also provide various protective functions to alleviate the dehydration-induced overproduction of toxic oxidative reactive agents and the disruption of membrane and protein structure and function (Bohnert and Shen, 1999). Studies have shown that compatible solute accumulation is correlated with salt tolerance (Popp and Smirnoff, 1995; Subbarao et al., 2001) and appears to be the most effective and fundamental adaptative mechanism for enhancing plant salt tolerance (Hare et al., 1998).

Metabolic osmotica fall into several classes, including nitrogenous compounds (quaternary ammonium compounds, polyamines, and free amino acids) and carbohydrates like sugars (sucrose, glucose, and fructose), polyols or sugar alcohols (mannitol, sorbitol, ononitol, D-pinitol, and inositols), and oligosaccharides (trehalose) (Hare et al., 1998; Williamson et al., 2002). The adaptive value of compatible solutes depends on whether their concentrations increase sufficiently in plant tissues experiencing increasing levels of salt stress (Gorham et al., 1981). With regard to sugar alcohols, D-pinitol, a methylated cyclitol, was found as a responsive metabolite, occurring in a number of halophytes such as mangrove species, Limonium gmelinii, and Mesembryanthemum crystallinum (Murakeözy et al., 2002; Paul and Cockburn, 1989; Popp, 
1984). Its compatibility has been confirmed, and its cellular location, biosynthetic pathway, and role in plant drought and salt tolerance have been studied in detail (Dittrich and Korak, 1984; Nguyen and Lamant, 1988; Orthen et al., 2000; Paul and Cockburn, 1989). Other cyclitols, such as chiro-inositol, have been found in halophytic species of Aegialitis annulata, L. gmelinii, and L. latifolium (Gagneul et al., 2007; Murakeözy et al., 2002; Popp, 1984). However, limited research has been done on their physiological role in salt tolerance, and to our knowledge, no research has even systematically shown whether their accumulation responds to an increasing series of osmotic or salt stresses.

The leadwort family, Plumbaginaceae, includes more than 50 halophytic Limonium species, many of which are known to complete their life cycles under hypersaline conditions [i.e., $56 \mathrm{dS} \cdot \mathrm{m}^{-1}$ (Aronson, 1989)]. Osmotic adjustment is achieved in the cytoplasm of these species through biosynthesis and accumulation of low-molecular-mass organic solutes. Previous research on their osmotic metabolite accumulation in response to salinity has focused mainly on betaines and other quaternary ammonium compounds (Hanson et al., 1991). Alarcón et al. (1999) speculated that soluble carbohydrates might contribute significantly to osmotic pressure buildup in L. latifolium. More recently, the experimental assessment of compatible solute function in L. latifolium salt tolerance revealed that the major organic contributors to its osmotic adjustment were chiroinositol and other soluble carbohydrates (Gagneul et al., 2007). Also, D-pinitol was identified in Hungarian inland native L. gmelinii as a significant component of the soluble carbohydrate pool, fluctuating with seasonal dynamic salt stress (Murakeözy et al., 2002). With regard to L. perezii and L. sinuatum, two valuable members in U.S. floral industry, what kinds of sugar or sugar alcohols they accumulate and how their carbohydrate pools respond to salt stress are still open questions. The goal of this study was to determine profiles of sugar and sugar alcohol accumulation in $L$. perezii and $L$. sinuatum grown under a wide range of saline treatments. Starch reserves were also examined to provide more comprehensive information on Limonium nonstructural carbohydrate accumulation in response to salinity.

\section{Materials and Methods}

Plant materials and growth conditions. The study consisted of two experiments conducted in greenhouse sand tank cultures at the USDA-ARS U.S. Salinity Laboratory, Riverside, CA (lat. $33^{\circ} 58^{\prime} 24^{\prime \prime} \mathrm{N}$, long. $117^{\circ} 19^{\prime} 12^{\prime \prime} \mathrm{W}$ ). The tanks measured $1.2 \times 0.6 \times 0.5 \mathrm{~m}$ deep and contained washed sand having an average bulk density of $1.4 \mathrm{Mg} \cdot \mathrm{m}^{-3}$. The sand had a volumetric water content at saturation of 0.34 and 0.1 $\mathrm{m}^{3} \cdot \mathrm{m}^{-3}$ after drainage had nearly ceased. Growth conditions and additional experimental details for Expt. 1 are as described in Grieve et al. (2005). Briefly, 15 seedlings of L. perezii cv. Blue Seas were transplanted into each of 21 sand tanks on 8 Feb. 2001; 15 seedlings of L. sinuatum cv. American Beauty were transplanted into each of a second set of 21 tanks on 16 Mar. 2001. Planting dates were staggered to assure that both species flowered at about the same time. Tanks were irrigated three times daily with a complete nutrient solution. This solution, with an electrical conductivity (EC) of $2.5 \mathrm{dS} \cdot \mathrm{m}^{-1}$, served as the control treatment. Salinizing salts were added to the nutrient solutions irrigating $L$. perezii on $15 \mathrm{Feb}$. and to those irrigating
L. sinuatum on 7 Apr. Treatments were designed to simulate saline-sodic wastewaters commonly present in the San Joaquin Valley (SJV) of California and from predictions based on appropriate simulations of what the long-term compositions of the water would be upon further concentration by plant-water extraction and evapotranspiration (Suarez and Simunek, 1997). The experimental design was a randomized block with seven salinities $\left(2.5,7,11,15,20,25\right.$, and $\left.30 \mathrm{dS} \cdot \mathrm{m}^{-1}\right)$ (Table 1), two Limonium species, and three replications.

Expt. 2 was conducted the next year (2002) in the same greenhouse sand tanks as described above. For this experiment, however, the test crop was $L$. perezii only and seeds were planted directly into the sand tanks on 18 Jan. 2002. After emergence, the plants were thinned to 15 seedlings per tank. The objective of this trial was to compare the response of $L$. perezii to two types of saline irrigation waters differing in ion composition. The composition of solution 1 was the same as used in Expt. 1 [i.e., SJV drainage water composition (sodium sulfatedominated)]. Solution 2 mimicked saline tailwaters often present in the inland valleys of southern California and essentially represents concentrations of Colorado River (CCR) water (sodium chloride system). ECs of the two irrigation water types were $2.5,6,8,10,12,16$, and $20 \mathrm{dS} \cdot \mathrm{m}^{-1}$ (Table 1). Simulations and predictions of the compositions followed Suarez and Simunek (1997). The salinization treatment was initiated at the same time that seeds were sown into the sand tanks. Growth conditions and additional experimental details are given in Carter et al. (2005). Treatments were replicated three times.

Chemicals. Chiro-inositol, myo-inositol, D-pinitol, and other chemicals unless mentioned were obtained from SigmaAldrich (Milwaukee).

Table 1. Compositions of salinizing salts in irrigation solutions simulating increasing salinities typical of those present in San Joaquin Valley (SJV) drainage waters and in saline tailwaters encountered in the inland valleys of southern California typically representing concentrations of Colorado River (CCR) water.

\begin{tabular}{|c|c|c|c|c|c|c|}
\hline $\begin{array}{l}\text { Salinity } \\
\text { type }\end{array}$ & $\begin{array}{c}\text { Total } \\
\text { salinity }\end{array}$ & $\mathrm{Ca}^{2+}$ & $\mathrm{Mg}^{2+}$ & $\mathrm{Na}^{+}$ & $\mathrm{SO}_{4}^{2-}$ & $\mathrm{Cl}^{-}$ \\
\hline \multicolumn{2}{|c|}{$\left(\mathrm{dS} \cdot \mathrm{m}^{-1}\right)$} & \multicolumn{5}{|c|}{$\left(\mathrm{mol} \cdot \mathrm{m}^{-3}\right)$} \\
\hline \multicolumn{7}{|l|}{ SJV } \\
\hline & 2.5 & 2.5 & 1.5 & 13.8 & 7.0 & 7.0 \\
\hline & 6.0 & 6.3 & 4.9 & 43.7 & 21.0 & 21.1 \\
\hline & 7.0 & 7.8 & 5.5 & 50.9 & 26.0 & 24.7 \\
\hline & 8.0 & 8.3 & 6.6 & 58.2 & 29.5 & 28.2 \\
\hline & 10.0 & 10.4 & 8.3 & 73.3 & 37.2 & 35.5 \\
\hline & 11.0 & 11.8 & 9.3 & 82.0 & 42.0 & 38.5 \\
\hline & 12.0 & 12.6 & 10.0 & 88.5 & 44.9 & 42.8 \\
\hline & 15.0 & 13.0 & 13.9 & 123.0 & 58.2 & 59.6 \\
\hline & 16.0 & 13.4 & 15.5 & 137.0 & 63.9 & 66.4 \\
\hline & 20.0 & 13.5 & 20.1 & 178.0 & 79.0 & 86.3 \\
\hline & 25.0 & 13.8 & 27.9 & 247.0 & 104.0 & 111.0 \\
\hline & 30.0 & 14.0 & 33.6 & 298.0 & 124.0 & 144.0 \\
\hline \multicolumn{7}{|l|}{ CCR } \\
\hline & 2.5 & 2.8 & 4.0 & 14.0 & 4.0 & 16.5 \\
\hline & 6.0 & 5.7 & 9.4 & 32.3 & 10.0 & 42.0 \\
\hline & 8.0 & 7.6 & 12.7 & 43.6 & 13.6 & 57.2 \\
\hline & 10.0 & 9.4 & 16.3 & 55.0 & 17.3 & 72.5 \\
\hline & 12.0 & 11.4 & 19.4 & 66.9 & 20.9 & 87.8 \\
\hline & 16.0 & 15.6 & 27.5 & 93.8 & 29.3 & 124.0 \\
\hline & 20.0 & 19.0 & 35.0 & 121.0 & 36.8 & 160.0 \\
\hline
\end{tabular}


SAMPle PREPARAtion. For Expt. 1, samples were taken on 21 Apr. 2001 for L. perezii (89 d old), and 8 May 2001 for L. sinuatum ( $53 \mathrm{~d}$ old) after both species had been exposed to salt treatments for a period of about $30 \%$ of their timeto-maturity days (67 d for L. perezii; $31 \mathrm{~d}$ for L. sinuatum). For Expt. 2, L. perezii was sampled 91 d (19 Apr. 2001) after application of salt stress. Two to five plants, depending on plant size, were taken from one tank as one replication. All samples were taken between 1130 and 1230 HR (midday) in the vegetative growth stage. Leaves of the sampled plants were immediately washed using deionized water and blotted dry. Samples were deep-frozen at $-80{ }^{\circ} \mathrm{C}$ and then freeze-dried at -48 to $-50{ }^{\circ} \mathrm{C}$ in a Freeze Dry System/Unitrap 10-102 (Virtis, Gardiner, NY) for $72 \mathrm{~h}$. The dried samples were ground in a Wiley mill to pass a 40 -mesh $(0.635 \mathrm{~mm})$ screen. For seedling nonstructural carbohydrate distribution, samples were taken directly from seedlings grown in vermiculite-filled tray pots and were processed as above.

Soluble CARbohydrate assay. Ground dried tissue $(0.1 \mathrm{~g})$ was weighed and incubated in $4 \mathrm{~mL}$ of $80 \%$ ethanol (v:v) in a $80{ }^{\circ} \mathrm{C}$ water bath with shaking for $30 \mathrm{~min}$ to extract soluble carbohydrates. Ethanol was decanted and the extraction was repeated three more times. A 4- to 6-mL portion of the pooled ethanol extract was dried in a Speed Vac Concentrator (SAVANT, Farmingdale, NY). The dried extracts were resuspended in $1 \mathrm{~mL}$ of deionized water, deionized through coupled anion and cation resin columns (AG1-X8/formate and AG50W$\mathrm{X} 8 / \mathrm{H}^{+}$; BIO-RAD, Hercules, CA) so that only neutral forms of the soluble carbohydrates were eluted with deionized water. All the eluate was taken to dryness in the Speed Vac Concentrator. The dried samples were redissolved in deionized water, filtered (0.22 $\mu \mathrm{m}$ pore size), and analyzed using a HPLC system with Dionex CarboPac PA1 column (Dionex, Sunnyvale, CA) connected to an ESA Autosampler (model 542; ESA, Bedford, MA). The separated carbohydrates were detected using an ESA Coulochem II Electrochemical Detector and quantified by comparison with known standards.

ISOLATION AND IDENTIFICATION OF CYCLITOLS. Aliquots of deionized samples and standards were applied to different lanes on Whatman No.1 filter paper sheet $(0.23 \times 0.58 \mathrm{~m})$. The paper chromatograms were developed in descending mode in a mobile phase of n-propanol:ethyl acetate:water $(7: 1: 2, \mathrm{v} / \mathrm{v})$ for 36 to $38 \mathrm{~h}$ for separation. The separated cyclitols were detected using the silver nitrate staining method (Trevelyan et al., 1950) and were identified by comparison with cyclitol standards. For further confirmation of chiro-inositol and myoinositol identity, the areas on unstained lanes for the two cyclitols were separately excised and cut into fine strips. The samples were then eluted into $10 \mathrm{~mL}$ of $50 \%$ ethanol at $55^{\circ} \mathrm{C}$ in a shaking water bath. This was repeated two more times, and the pooled eluate was filtered $(0.45 \mu \mathrm{m}$ pore size $)$ and dried in a Speed Vac Concentrator. The resulting pellets were redissolved in deuterium oxide, filtered through a $0.22-\mu \mathrm{m}$ filter, and identified using an INOVA300 nuclear magnetic resonance (NMR) spectrometer (Varian, Palo Alto, CA) at $500 \mathrm{MHz}\left({ }^{1} \mathrm{H}\right)$ according to Ichimura et al. (1998).

STARCH ASSAY. The assay was based on procedures used by Liu et al. (1999). The extracted residues were oven dried at $55^{\circ} \mathrm{C}$, suspended in $2.0 \mathrm{~mL}$ of $2 \mathrm{~N} \mathrm{KOH}$, and boiled for $1 \mathrm{~h}$ to gelatinize the starch. After cooling, the sample was mixed with $2.0 \mathrm{~mL}$ of $2 \mathrm{~N}$ acetic acid to adjust its $\mathrm{pH}$ to 4.5 . The starch was then hydrolyzed to glucose using amyloglucosidase (Fluka,
Ronkonkoma, NY; 93 units per sample). The resulting glucose was detected with a glucose kit (HK20; Sigma-Aldrich) using a

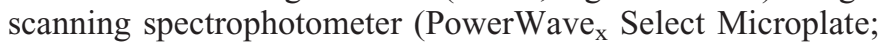
Bio-Tek, Winooski, VT) at $340 \mathrm{~nm}$, and was quantified by comparison with a known glucose standard.

Phloem sap collection and analysis. The experimental protocol for phloem exudate collection was essentially that used by Liu et al. (2002). Fully expanded leaves were excised midday in full sun, and their petiole ends were immersed in deionized water and transferred to the laboratory from the greenhouse. The excised petiole ends were then immersed in

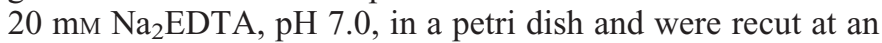
angle leaving a stub of a standard 2 to $3 \mathrm{~mm}$ length attached to the leaf base. The petiole stub was then immersed in $20 \mathrm{~mm}$ $\mathrm{Na}_{2}$ EDTA, $\mathrm{pH} 7.0$, in a $1.5-\mathrm{mL}$ microcentrifuge tube. Phloem exudation was allowed to proceed under ambient room light and temperature conditions and the exudates were deionized and analyzed for carbohydrates as outlined above.

Statistical analysis. The significance of salt effects on sugar, polyol, and starch concentrations and of their differences between species or between salt compositions were analyzed at $P \leq 0.05$ using GLM and TTEST procedures, respectively, in SAS (version 8.2; SAS Institute, Cary, NC).

\section{Results}

OCCURRENCE OF CHIRo-InOSITOL. Paper chromatography and HPLC analyses showed that $L$. perezii and $L$. sinuatum possibly contained not only myo-inositol but also chiro-inositol. NMR ${ }^{1} \mathrm{H}$ spectra for the two individual isolated polyols had all the peaks with the same chemical shift sets as for myo-inositol and chiro-inositol standards, respectively. This confirmed that not only myo-inositol but also the rare cyclitol chiroinositol (Fig. 1) occurred in both species. Because we did not examine the stereocenter of the isolated chiro-inositol, D-chiro-inositol and L-chiro-inositol have the same HPLC retention time, paper chromatography mobility, and NMR spectrum (data not shown), we are uncertain at this time whether D- or L- or both types of chiro-inositol occurred in the Limonium species examined. Here, it is simply reported as chiro-inositol. Murakeözy et al. (2002) reported that L. gmelinii ssp. hungarica accumulated pinitol, a common stress-inducible cyclitol, as one of its prominent soluble carbohydrates. We particularly examined whether these two Limonium species accumulated pinitol using HPLC, paper chromatography, and NMR. However, pinitol was not detected in the shoots of $L$. perezii or L. sinuatum under salt or nonsalt stress conditions.

Distribution OF SOLUBLE CARBOHYDRATES AND STARCH IN SEEDLINGS. In addition to chiro-inositol and myo-inositol, fructose, glucose, and sucrose were also detected in L. perezii and L. sinuatum. These three common sugars accounted for more than $92 \%$ of the total soluble carbohydrates (w/w) in 29d-old seedlings before salt treatment (Table 2). Chiro-inositol and myo-inositol accounted for the remaining 8\%. Only small amounts of these two inositols were found in leaves and roots and their concentrations did not exceed 2.7 and $15.7 \mu \mathrm{mol} \cdot \mathrm{g}^{-1}$ dry weight for chiro-inositol and myo-inositol, respectively (Table 2). The other major carbohydrate reserve form, starch, accumulated mainly in the leaves, with concentrations of 166 and $204 \mathrm{mg} \cdot \mathrm{g}^{-1}$ dry weight for L. perezii and L. sinuatum, respectively. In the roots, starch concentration was low, with 

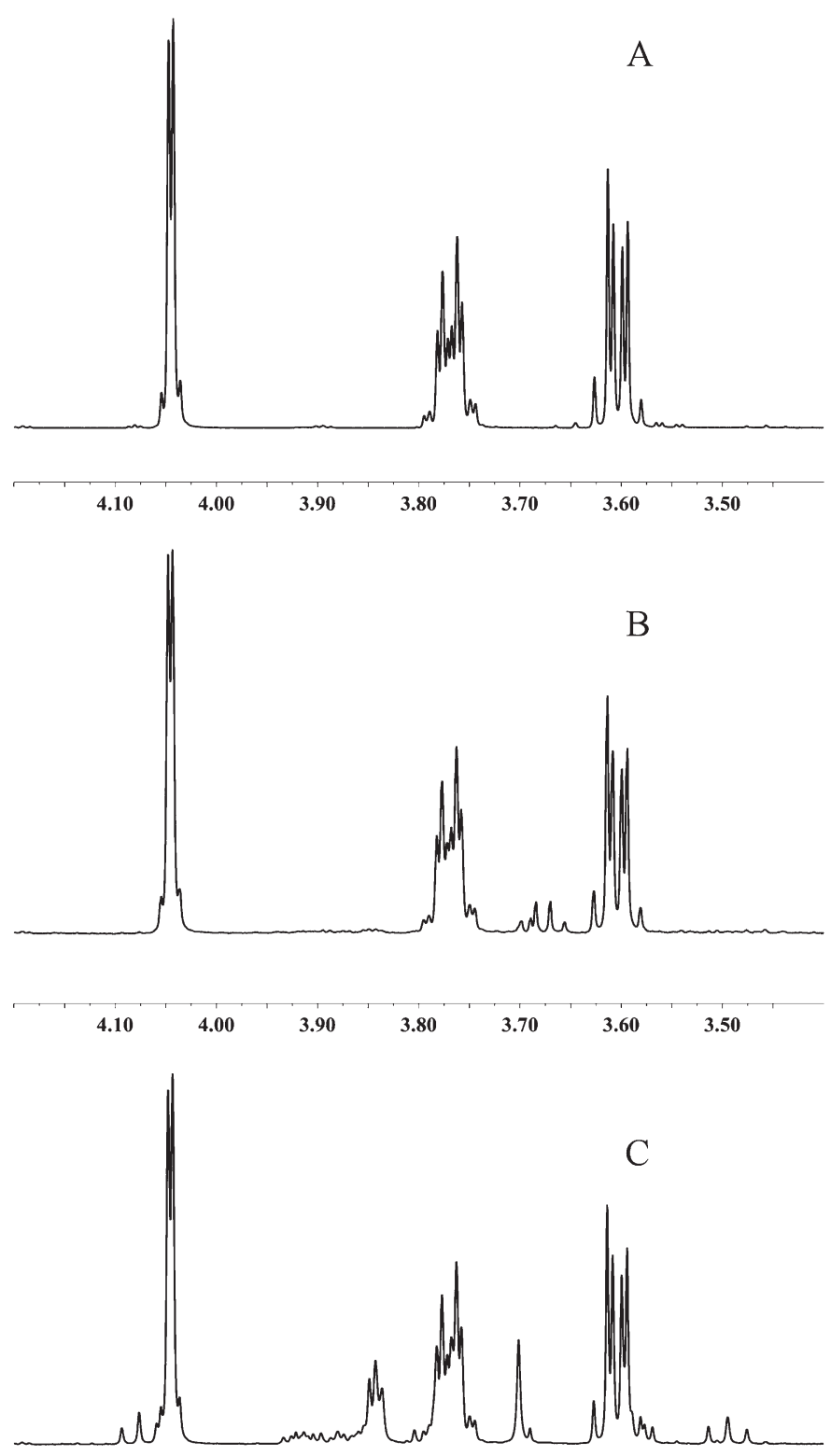

\begin{tabular}{llccccc}
\hline 4.10 & 4.00 & 3.90 & 3.80 & 3.70 & 3.60 & 3.50 \\
& Chemical shift $(\mathrm{ppm})$ &
\end{tabular}

Fig. 1. Proton nuclear magnetic resonance ( ${ }^{1} \mathrm{H}$ NMR) spectra of chiro-inositol, standard (A) and isolated from Limonium perezii (B), and Limonium sinuatum (C) leaves. Additional peaks in the isolated samples are sample noise peaks.

the values of 26.5 and $25.8 \mathrm{mg} \cdot \mathrm{g}^{-1}$ dry weight for L. perezii and L. sinuatum, respectively (Table 2).

RESPONSE OF CARBOHYDRATE ACCUMULATION TO SALINITY. Soluble carbohydrate and starch concentrations in the leaves of salt-stressed plants were determined (Fig. 2). Chiro-inositol and myo-inositol concentrations were low in nonsalt-stressed plants, with the lowest values being 6.4 and 17.1 (L. perezii), and 2.6 and 10.4 (L. sinuatum) $\mu \mathrm{mol} \cdot \mathrm{g}^{-1}$ dry weight, respectively (Fig. 2, A and B). Increased leaf chiro-inositol accumulation correlated with increased salinity for both Limonium species. As salinity increased to $30 \mathrm{dS} \cdot \mathrm{m}^{-1}$, leaf chiro-inositol concentration increased significantly $(P \leq 0.05)$, reaching 52.8 and $72.9 \mu \mathrm{mol} \cdot \mathrm{g}^{-1}$ dry weight for $L$. perezii and L. sinuatum, respectively (Fig. 2A). Compared with concentrations in unstressed leaves, these values were 8.3- and 28.0-fold higher for $L$. perezii and $L$. sinuatum, respectively. Under salt stress conditions, chiro-inositol became the predominant carbohydrate. Myo-inositol concentration in each species, however, was not significantly $(P>0.05)$ affected as salinity increased from 2.5 to $30 \mathrm{dS} \cdot \mathrm{m}^{-1}$ (Fig. 2B). Overall, no significant $(P>0.05)$ difference in leaf cyclitol accumulation between the two Limonium species was found in response to increasing salinity (Fig. 2, A and B).

Significant $(P \leq 0.05)$ differences of leaf hexose (glucose and fructose) concentrations for both species were found at different salinity levels (Fig. 2, C and D). Specifically, leaf hexose concentrations in $L$. perezii increased as salinity increased and then reached a plateau when salinity reached 15 and $10 \mathrm{dS} \cdot \mathrm{m}^{-1}$ for fructose and glucose, respectively. In contrast, hexoses were relatively constant in L. sinuatum under salt stress conditions. Sucrose concentration decreased significantly $(P \leq 0.05)$ from 57.0 to $14.7 \mu \mathrm{mol} \cdot \mathrm{g}^{-1}$ dry weight in $L$. perezii but showed no significant $(P>0.05)$ change in L. sinuatum as salinity increased from 2.5 to $30 \mathrm{dS} \cdot \mathrm{m}^{-1}$ (Fig. $2 \mathrm{E})$. As a result, leaves of $L$. sinuatum had higher sucrose concentration than those of $L$. perezii under salt stress. However, no significant $(P>0.05)$ difference in salt effect was found on the sum of the three common sugar concentrations between species. Overall, there was a significant $(P \leq$ 0.05 ) salt effect on leaf total soluble carbohydrate concentration for both species. In L. sinuatum, leaf total soluble carbohydrate concentration increased from 178.7 to $253.7 \mu \mathrm{mol} \cdot \mathrm{g}^{-1}$ dry weight as salinity increased from 2.5 to $30 \mathrm{dS} \cdot \mathrm{m}^{-1}$ (Fig. $2 \mathrm{~F}$ ). In $L$. perezii, leaf total soluble carbohydrate level increased with increasing salt stress from 151.2 to reach a plateau around $251.3 \mu \mathrm{mol} \cdot \mathrm{g}^{-1}$ dry weight at a salinity of $15 \mathrm{dS} \cdot \mathrm{m}^{-1}$ (Fig. $2 \mathrm{~F}$ ). No significant $(P>0.05)$ salt effect was found on leaf starch concentration in either Limonium species (Fig. 2G).

While salinity did not alter total carbohydrate content, it did alter carbon partitioning between soluble carbohydrates, as shown by the significant $(P \leq 0.05)$ increase in the ratio of chiro-inositol over the sum of fructose, glucose, and sucrose from 0.034 to 0.29 (L. perezii) and from 0.012 to 0.32 (L. sinuatum) as salinity increased from its control level to 30 $\mathrm{dS} \cdot \mathrm{m}^{-1}$ (Fig. $2 \mathrm{H}$ ), a 8.5- and 26.7-fold increase for L. perezii and L. sinuatum, respectively.

Expt. 2 was designed to compare sugar, polyol, and starch accumulation in $L$. perezii grown under conditions mimicking SJV drainage water salt composition versus CCR drainage water salt composition. Essentially, leaf chiro-inositol, myoinositol, fructose, glucose, sucrose, and starch concentrations as well as the ratio of chiro-inositol content over the sum of fructose, glucose, and sucrose in response to either type of salinity (Fig. 3) echoed what were found in Expt. 1 with $L$. perezii grown in a salinity range from 2.5 to $20 \mathrm{dS} \cdot \mathrm{m}^{-1}$ (Fig. 2). Overall, the relatively higher $\mathrm{SO}_{4}{ }^{2-}$ and lower $\mathrm{Cl}^{-}$constituents found in SJV drainage water compared with CCR waters (Table 1) resulted in no significant $(P>0.05)$ difference in total soluble carbohydrate or starch concentrations in L. perezii leaves under the different salinities (Fig. 3, A-G). The same was true for the carbon partitioning, the ratio of chiro-inositol over the sum of fructose, glucose, and sucrose (Fig. 3H).

Phloem transportation of Chiro-inositol. Detached source leaves of $L$. perezii exuded sugars and sugar alcohols 
Table 2. Distribution of soluble carbohydrates and starch in the leaves and roots of Limonium perezii and Limonium sinuatum of 29-d-old seedlings (with a dry shoot biomass of $0.024 \mathrm{~g}$ and $0.38 \mathrm{~g}$ per plant for L. perezii and L. sinuatum, respectively) grown under nonsalt-stress condition.

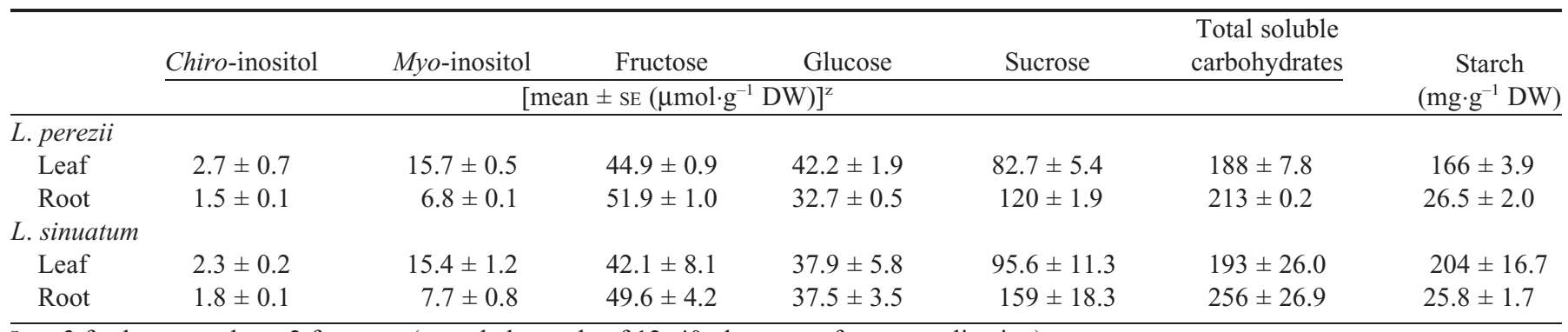

${ }_{\mathrm{z}} \mathrm{n}=3$ for leaves and $\mathrm{n}=2$ for roots (a pooled sample of $12-40$ plants was for one replication).

from their petioles into Na-EDTA solutions (Fig. 4). Chiroinositol and myo-inositol were phloem-transportable, but apparently much more chiro-inositol was exuded than myoinositol (Fig. 4, A and B). Sucrose and chiro-inositol were the predominant carbohydrates in phloem-exuded sap. Salt-stressed leaves exuded significantly $(P \leq 0.05)$ more chiro-inositol than did nonsalt-stressed leaves throughout the exudation period (Fig. 4A), which made chiro-inositol the predominant soluble carbohydrate on a molar basis (Fig. 4, A and C). The amounts of exuded chiro-inositol reached 0.023 and $0.078 \mu \mathrm{mol} \cdot \mathrm{g}^{-1}$ dry weight after $12 \mathrm{~h}$ exudation for nonsalt-stressed and saltstressed leaves, respectively. However, differences in the

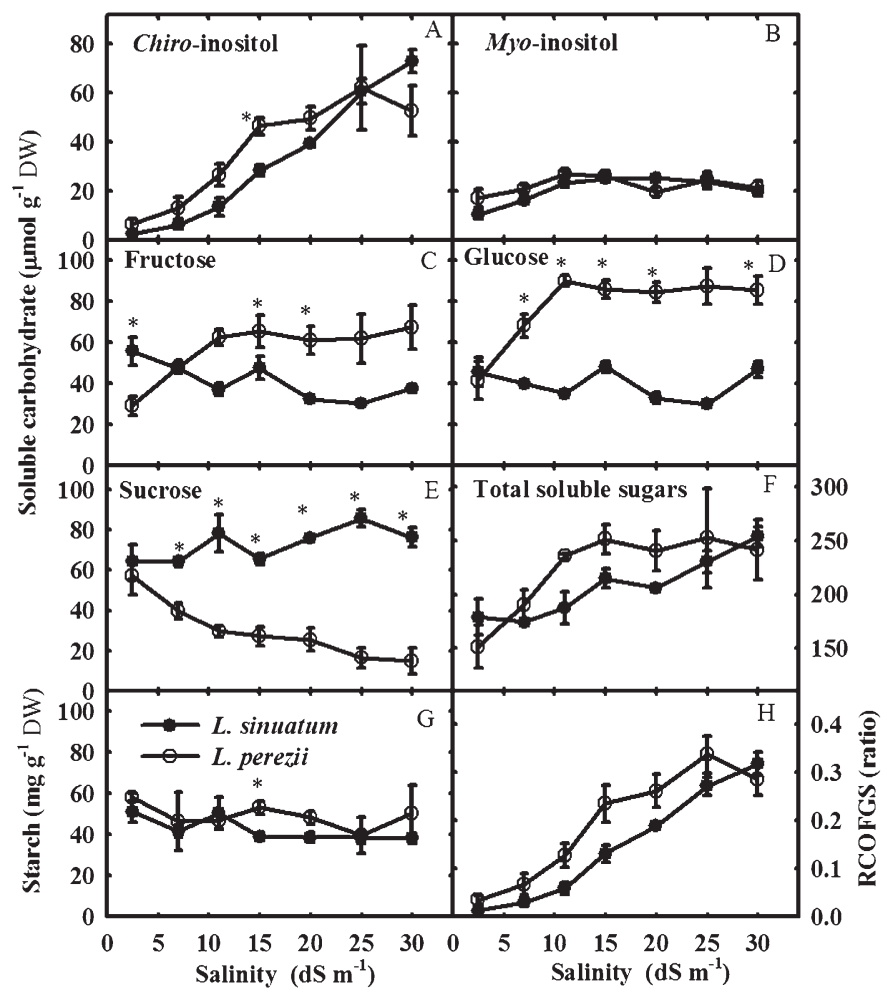

Fig. 2. Limonium perezii and Limonium sinuatum leaf soluble carbohydrate (A$\mathbf{F})$ and starch $(\mathbf{G})$ concentrations, and the ratio of chiro-inositol over the sum of fructose + glucose + sucrose $($ RCOFGS) $(\mathbf{H})$ in response to salinity (San Joaquin Valley drainage water salt composition). Total soluble carbohydrates are the sum of all the detected sugars and sugar alcohols. Vertical bars represent \pm SE, $\mathrm{n}=3$ (tanks). Significant difference $(P \leq 0.05)$ between the two species is marked with an asterisk at any given salinity level. amount of myo-inositol or sucrose exuded between nonsaltand salt-stressed leaves were not significant $(P>0.05)$ over the exudation period (Fig. 4, B and C). In late exudation period, the amount of sucrose exuded by non-stressed leaves appeared higher than that of stressed leaves (Fig. 4C).

\section{Discussion}

We have here demonstrated the presence of chiro-inositol in $L$. perezii and L. sinuatum. Recently, chiro-inositol was detected and quantified in L. latifolium (Gagneul et al., 2007).

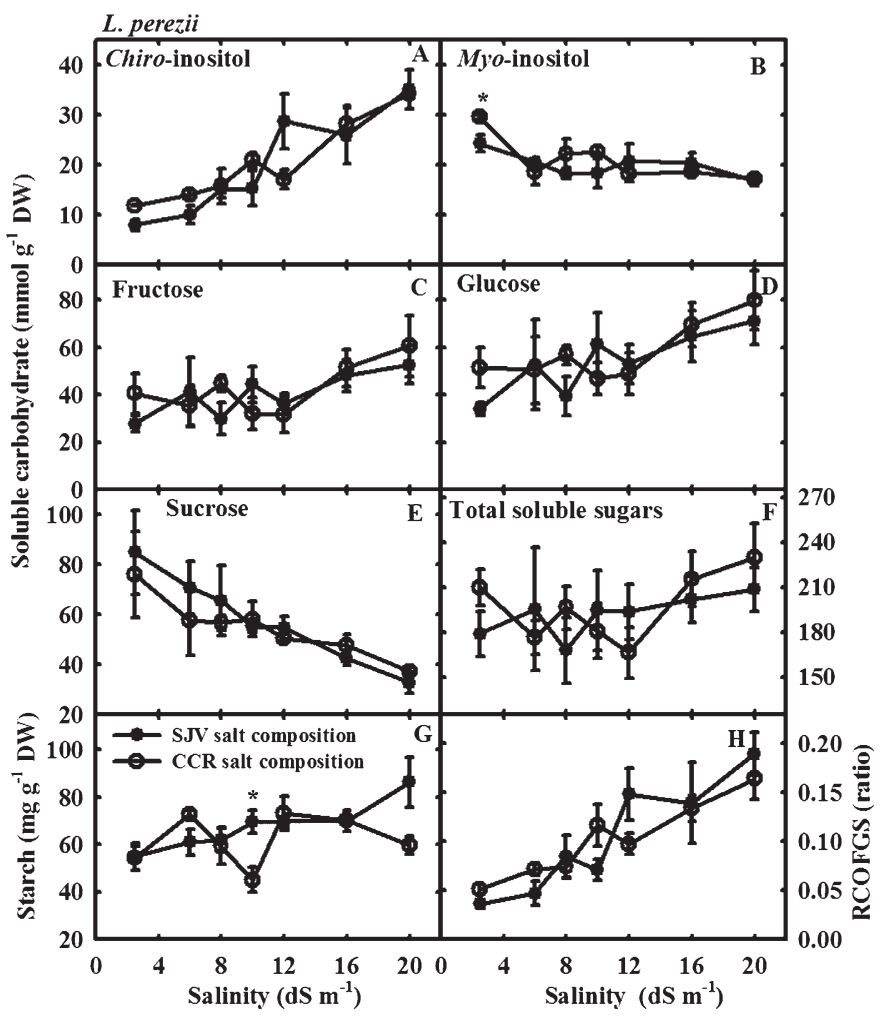

Fig. 3. Comparison of responses of Limonium perezii leaf soluble carbohydrates (A-F) and starch (G) concentrations, and ratio of chiro-inositol over the sum of fructose + glucose + sucrose (RCOFGS) (H) to two salt compositions, San Joaquin Valley (SJV) drainage waters versus saline tailwaters encountered in the inland valleys of southern California typically representing concentrations of Colorado River (CCR) water. Total soluble carbohydrates are the sum of the all detected sugars and sugar alcohols. Vertical bars represent $\pm \mathrm{SE}, \mathrm{n}=3$ (tanks). Significant difference $(P \leq 0.05)$ between the two salt compositions is marked with an asterisk at any given salinity level. 


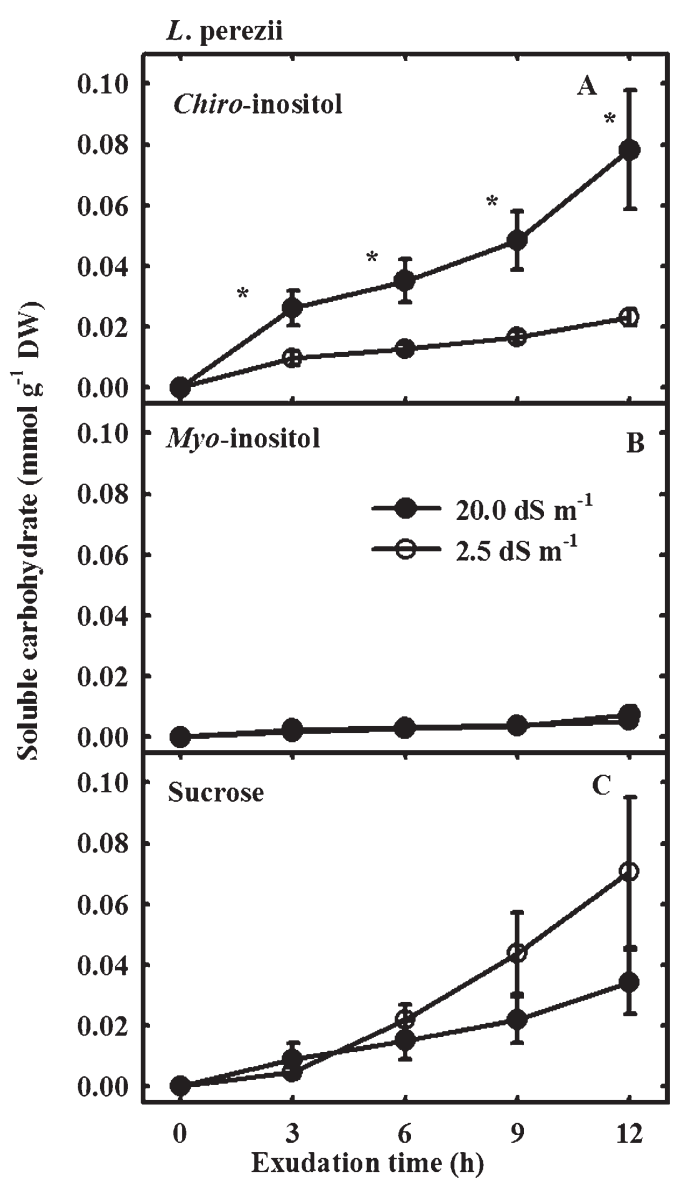

Fig. 4. Cumulative phloem exudation of cyclitols (A and $\mathbf{B}$ ) and sucrose (C) from fully expanded leaves of Limonium perezii under salt $\left(20.0 \mathrm{dS} \cdot \mathrm{m}^{-1}\right)$ and nonsalt stress $\left(2.5 \mathrm{dS} \cdot \mathrm{m}^{-1}\right)$. The two sources of saline water, San Joaquin Valley drainage waters versus saline tailwaters encountered in the southern inland valleys of California typically representing concentrations of Colorado River water, had the same effect on the carbohydrate exudation, and thus the data were pooled. Vertical bars represent \pm SE, $n=8$ (leaves). Significant salt effect at each exudation period $(P \leq 0.05)$ is marked with an asterisk at any given salinity level.

Murakeözy et al. (2002) reported that L. gmelinii possibly contained chiro-inositol, but gave no quantitative information for this cyclitol. Instead, they confirmed pinitol occurrence and quantified its level in L. gmelinii. This suggests that specific cyclitol accumulation may be a species-characteristic physiological feature for halophytic Limonium species.

Under nonsalt-stressed conditions, chiro-inositol apparently is not a significant metabolite, like the compatible solutes pinitol and betaine (Paul and Cockburn, 1989; Popp and Smirnoff, 1995; Orthen et al., 2000; Rhodes and Hanson, 1993). Very low chiro-inositol concentrations in leaves and roots of the seedlings before salt treatment precluded the possibility that a concentrating effect caused by growth rate reduction due to salt stress (Grieve et al., 2005) might be responsible for the high measured chiro-inositol level. Instead, the increase in chiro-inositol concentration with increasing salinity was an active response through its enhanced synthesis in response to salt stress, which resulted in more carbon allocated to chiro-inositol per unit of biomass formation.

Leaves of the both salt-stressed Limonium species accumulated amounts of salts (Grieve et al., 2005) that would be toxic to cytoplasmic function if they were not restricted to the vacuoles. The observed increase in chiro-inositol accumulation might counteract a high vacuolar ion accumulation by increasing cytoplasmic $\psi_{\mathrm{S}}$. To appropriately contribute to osmotic adjustment, osmolytes should be stress-inducible and probably in a range between 40 and $400 \mu \mathrm{mol} \cdot \mathrm{g}^{-1}$ (Subbarao et al., 2001). Leaf chiro-inositol concentration in both Limonium species was $40 \mu \mathrm{mol} \cdot \mathrm{g}^{-1}$ or higher under moderate $\left(15-20 \mathrm{dS} \cdot \mathrm{m}^{-1}\right)$ or higher salt stress, thus contributing significantly to osmotic adjustment. Evidence of cytoplasmic localization of chiro-inositol would further verify this function, although its location might be similar to that of pinitol, which was found in cytoplasm but not in vacuoles (Paul and Cockburn, 1989). Fructose, glucose, and sucrose are metabolically labile compounds whose function as compatible cytosolutes is debatable (Gorham et al., 1981). Some experiments on the impact of these solutes on enzymatic activities showed that, in fact, they might be incompatible and more often found in vacuoles (Rozema et al., 1978; Wagner, 1979). Chiro-inositol, on the other hand, is quite inert (Popp and Smirnoff, 1995), thus supporting the notion (Gorham et al., 1981) that polyols have little effect on enzyme activities and are more compatible than other solutes. The increase in chiro-inositol accumulation observed here mainly accounted for the altered carbon partitioning between chiro-inositol and the three common sugars under salt stress, implying that the cells might require more chiro-inositol rather than the common sugars to deal with salinity increase. In addition, myo-inositol was present in only small amounts and showed little response to salinity. Thus, chiro-inositol appears more significant than the other carbohydrates in playing an adaptive role for Limonium species salt tolerance.

The observed levels of chiro-inositol in $L$. perezii and L. sinuatum were similar to levels of D-pinitol in L. gmelinii (Murakeözy et al., 2002) and might function similarly in response to salt stress. Under salt stress, structures and functions of membranes and enzymes are subjected to salt damage, and toxic radical oxygen species production may be enhanced to levels causing leaf necrosis (Bohnert and Shen, 1999; Hernández et al., 2001; Mittova et al., 2003). Polyols have water-like hydrogen-hydroxyl groups and can contribute to maintaining an ordered hydration shell around the surface of proteins or membranes and stabilizing protein structures, thus preventing metabolic inactivation under low $\psi_{\mathrm{S}}$ (Timasheff, 1993; Williamson et al., 2002). In addition, polyols have been reported to be effective scavengers of radical oxygen species (Orthen et al., 1994). L. perezii and L. sinuatum survived all salt treatments and completed their life cycles without any visual symptoms of stress (Grieve et al., 2005). The increased chiro-inositol accumulation that paralleled increased salt stress might then be involved in protecting plants from salt-stress damages.

Chiro-inositol can be synthesized by a one-step isomerization of myo-inositol or through the direct cyclization of glucose by a cyclo-aldolase (Drew, 1984; Taguchi et al., 1997). Either pathway is simpler than the pathway leading to D-pinitol formation, which occurs through methylation of myo-inositol to produce ononitol and the subsequent isomerization of ononitol to pinitol (Dittrich and Korak, 1984). The production of methyl groups used in pinitol synthesis involves photorespiration (Hare et al., 1998), which leads to $\mathrm{H}_{2} \mathrm{O}_{2}$ production and thus increases the potential for oxidative damage to the cell. We 
speculate that the accumulation of chiro-inositol instead of D-pinitol might reduce $\mathrm{H}_{2} \mathrm{O}_{2}$ production, thus favoring the adaptation of these plants to salt stress.

As had been reported for L. gmelinii (Murakeözy et al., 2002), we found that $L$. perezii and L. sinuatum have high levels of soluble carbohydrate. Although also found in high amounts, nitrogenous compounds found in L. latifolium could not by themselves fully account for the metabolite contribution to leaf cell osmotic adjustment (Gagneul et al., 2007). It appears rather that halophytic Limonium species accumulate nitrogenous compounds and soluble carbohydrates in high amounts. Here, we found that overall carbohydrate reserves (total soluble sugars, polyols, and starch) in L. perezii and L. sinuatum appeared to be adequate even though more chiro-inositol was synthesized under salt stress. A decrease in sucrose concentration accompanied by an increase in fructose and glucose concentrations was observed in $L$. perezii but not in L. sinuatum. L. sinuatum is more salt tolerant than $L$. perezii (Grieve et al., 2005). Whether the differential response of the three individual common sugars to salinity was related to differences in salt tolerance between the two Limonium species is still to be resolved.

Treatments using sulfate-dominated SJV drainage waters resulted in relatively higher sulfur and sodium but less calcium and chloride accumulation in the leaves than did treatments based on sodium chloride dominated CCR salts (Carter et al., 2005). Differences in composition of the irrigation waters and the resulting differences in specific ion accumulation, however, had little effect on plant carbohydrate accumulation.

Because chiro-inositol and myo-inositol are phloemtransportable, these polyols are readily translocated from leaves to roots, which links leaf cyclitol pool to roots. For halophytes, this cyclitol phloem flux appears particularly important. In M. crystallinum, stress-inducible ononitol and its precursor, myo-inositol, act as a leaf-to-root signal. This facilitates sodium uptake and translocation through the xylem to leaves, leading to a transition from a nontolerant to a salinity-tolerant state (Nelson et al., 1999). Chiro-inositol phloem-transportation was observed here to be enhanced by salt stress, suggesting a similar correlation between higher salt uptake and higher amounts of cyclitol translocated to roots in Limonium species. More evidence on the role of chiro-inositol in regulation of salt accumulation is needed for a further understanding of salt tolerance of Limonium species.

Chiro-inositol accumulation in response to salinity appears an important feature of Limonium salt stress tolerance. Almost all of our modern crops are derived from glycophytes and thus lack a genetic basis for salt tolerance (Glenn et al., 1999). Targeting production of low-molecular-weight solutes is one of the primary strategies currently used for improving crop salt tolerance through breeding or by molecular transformation (Bohnert and Shen, 1999; Nuccio et al., 1999). Because the biosynthesis of chiro-inositol needs just one step from myoinositol or glucose, this potentially makes it a better candidate for bioengineering salt tolerance than pinitol, whose synthesis requires relatively one more step. Future progress in characterizing chiro-inositol biosynthesis in the Limonium species may provide a basis for its bioengineering transfer, which in turn, may provide valuable information on the physiological function of chiro-inositol accumulation in plant adaptation to salt stress.

\section{Literature Cited}

Alarcón, J.J., M.A. Morales, A. Torrecillas, and M.L. Sánchez-Blanco. 1999. Growth, water relations and accumulation of organic and inorganic solutes in the halophyte Limonium latifolium cv. Avignon and its interspecific hybrid Limonium caspia $\times$ Limonium latifolium cv. Beltlaard during salt stress. J. Plant Physiol. 154:795-801.

Aronson, J.A. 1989. HALOPH. A data base of salt tolerant plants of the world. Office of Arid Lands Studies. Univ. Arizona, Tucson.

Bohnert, H.J. and B. Shen. 1999. Transformation and compatible solutes. Scientia Hort. 78:237-260.

Carter, C.T., C.M. Grieve, and J.A. Poss. 2005. Salinity effects on emergence, survival, and ion accumulation of Limonium perezii. J. Plant Nutr. 28:1243-1257.

Dittrich, P. and A. Korak. 1984. Novel biosynthesis of D-pinitol in Simmondsia chinensis. Phytochemistry 23:65-66.

Drew, E.A. 1984. Physiology and metabolism of cyclitols, p. 133-155. In: D.H. Lewis (ed.). Storage carbohydrates in vascular plants. Cambridge Univ. Press, Cambridge, UK.

Flowers, T.J., M.A. Hajibagheri, and N.J.W. Clipson. 1986. Halophytes. Quarterly Rev. Biol. 61:313-337.

Gagneul, D., A. Aïnouche, C. Duhazé, R. Lugan, F.R. Larher, and A. Bouchereau. 2007. A reassessment of the function of the so-called compatible solutes in the halophytic Plumbaginaceae Limonium latifolium. Plant Physiol. 144:1598-1611.

Glenn, E.P., J.J. Brown, and E. Blumwald. 1999. Salt tolerance and crop potential of halophytes. Crit. Rev. Plant Sci. 18:227-255.

Gorham, J., L. Hughes, and R.G. Wyn Jones. 1981. Low-molecularweight carbohydrates in some salt-stressed plants. Physiol. Plant. 53:27-33.

Grieve, C.M., J.A. Poss, S.R. Grattan, P.J. Shouse, J.H. Lieth, and L. Zeng. 2005. Productivity and mineral nutrition of Limonium species irrigated with saline wastewaters. HortScience 40:654-658.

Hanson, A.D., B. Rathinasabapathi, B. Chamberlin, and D.A. Gage. 1991. Comparative physiological evidence that $\beta$-alanine betaine and choline- $O$-sulfate act as compatible osmolytes in halophytic Limonium species. Plant Physiol. 97:1199-1205.

Hare, P.D., W.A. Cress, and J.V. Staden. 1998. Dissecting the roles of osmolyte accumulation during stress. Plant Cell Environ. 21:535553.

Hernández, J.A., M.A. Ferrer, A. Jiménez, A.R. Barceló, and F. Sevilla. 2001. Antioxidant systems and $\mathrm{O}_{2}-/ \mathrm{H}_{2} \mathrm{O}_{2}$ production in the apoplast of pea leaves. Its relation with salt-induced necrotic lesions in minor veins. Plant Physiol. 127:817-831.

Ichimura, K., K. Kohata, M. Koketsu, M. Shimamura, and A. Ito. 1998. Identification of pinitol as a main sugar constituent and changes in its content during flower bud development in carnation (Dianthus caryophyllus L.). J. Plant Physiol. 152:363-367.

Liu, X., J. Sievert, M.L. Arpaia, and M.A. Madore. 2002. Postulated physiological roles of the seven-carbon sugars, mannoheptulose, and perseitol in avocado. J. Amer. Soc. Hort. Sci. 127:108-114.

Liu, X., P.W. Robinson, M.A. Madore, G.W. Witney, and M.L. Arpaia. 1999. 'Hass' avocado carbohydrate fluctuations. I. Growth and phenology. J. Amer. Soc. Hort. Sci. 124:671-675.

Mittova, V., M.T.M. Volokita, and M. Guy. 2003. Up-regulation of the leaf mitochondria and peroxisomal antioxidative systems in response to salt-induced oxidative stress in the wild salt-tolerant tomato species Lycopersicon pennellii. Plant Cell Environ. 26:845856.

Murakeözy, É.P., N. Smirnoff, Z. Nagy, and Z. Tuba. 2002. Seasonal accumulation pattern of pinitol and other carbohydrates in Limonium gmelinii subsp. hungarica. J. Plant Physiol. 159:485-490.

Nelson, D.E., M. Koukoumanos, and H.J. Bohnert. 1999. Myoinositol-dependent sodium uptake in ice plant. Plant Physiol. 119:165-172.

Nguyen, A. and A. Lamant. 1988. Pinitol and myo-inositol accumulation in water-stressed seedlings of maritime pine. Phytochemistry 27:3423-3427. 
Nuccio, M.L., D. Rhodes, S.D. McNeil, and A.D. Hanson. 1999. Metabolic engineering of plants for osmotic stress resistance. Curr. Opin. Plant Biol. 2:128-134.

Orthen, B., M. Popp, and N. Smirnoff. 1994. Hydroxyl radical scavenging properties of cyclitols. Proc. Royal Soc. Edinburgh 102B:269-272.

Orthen, B., M. Popp, and W. Barz. 2000. Cyclitol accumulation in suspended cells and intact plants of Cicer arietinum L. J. Plant Physiol. 156:40-45.

Paul, M.J. and W. Cockburn. 1989. Pinitol, a compatible solute in Mesembryanthemum crystallinum L.? J. Expt. Bot. 40:1093-1098.

Popp, M. 1984. Chemical composition of Australian mangroves. II. Low molecular weight carbohydrates. Zeitschrift fur Pflanzenphysiologie 113:411-421.

Popp, M. and N. Smirnoff. 1995. Polyol accumulation and metabolism during water deficit, p. 199-215. In: N. Smirnoff (ed.). Environment and plant metabolism, flexibility and acclimation. Bios Scientific Publ., Oxford, UK.

Rhodes, D. and A.D. Hanson. 1993. Quaternary ammonium and tertiary sulfonium compounds in higher plants. Annu. Rev. Plant Physiol. Plant Mol. Biol. 44:357-384.

Rozema, J., D.A.G. Buizer, and H.E. Fabritius. 1978. Population dynamics of Glaux maritima and eco-physiological adaptations to salinity and inundation. Oikos 30:539-548.
Suarez, D.L. and J. Simunek. 1997. UNSATCHEM: Unsaturated water and solute transport model with equilibrium and kinetic chemistry. Soil Sci. Soc. Amer. J. 61:1633-1646.

Subbarao, G.V., L.H. Levine, and G.W. Stutte. 2001. Glycine betaine accumulation: Its role in stress resistance in crop plants, p. 881-907. In: M. Pessarakli (ed.). Handbook of plant and crop physiology. Marcel Dekker, New York/Basel.

Taguchi, R., J. Yamazaki, Y. Tsutsui, and H. Ikezawa. 1997. Identification of chiro- inositol and its formation by isomerization of myo-inositol during hydrolysis of glycosylphosphatidylinositolanchored proteins. Arch. Biochem. Biophys. 342:161-168.

Timasheff, S.N. 1993. The control of protein stability and association by weak interactions with water: How do solvents affect these processes? Annu. Rev. Biophys. Biomol. Struct. 22:6797.

Trevelyan, W.E., D.P. Procter, and J.S. Harrison. 1950. Detection of sugars on paper chromatograms. Nature 166:444-445.

Wagner, G.J. 1979. Content and vacuole/extravacuole distribution of neutral sugars, free amino acids, and anthocyanin in protoplasts. Plant Physiol. 64:88-93.

Williamson, J.D., D.B. Jennings, W.-W. Guo, D.M. Pharr, and M. Ehrenshaft. 2002. Sugar alcohols, salt stress, and fungal resistance: Polyols-multifunctional plant protection? J. Amer. Soc. Hort. Sci. 127:467-473. 